\title{
Effect of school bags on body mechanics among Saudi children
}

\author{
Fayz S Al Shahry, ${ }^{1}$ Hind Abdulrahman Almahmoud ${ }^{2}$, Razan Ibrahim Alhujairy ${ }^{2}$ and Khalood \\ Khalid Aljohi² \\ ${ }^{1}$ Assistant Prof. CAMS, KSAU-HS, Consultant Neurorehabilitation Service, King Abdulaziz Medical City, Riyadh \\ ${ }^{2}$ Student, Occupational Therapy, CAMS, KSAU-HS, Riyadh Saudi Arabia
}

\begin{abstract}
It is well known that school bag has effects on the posture of early school students. Therefore, lack of data about the impact of school bags on body mechanics of children from Saudi Arabia.This study aimed to assess the effect of heavy school bag on the student's body mechanics at elementary school in Riyadh. We conducted this observational cross-sectional study by observing the posture, palpation meter (PALM), interview, and examining school bag content, of primary school students across the Riyadh. Total of 200 students was included in our study. Less than half of the students reported pain (41.5\%). Students who reported pain $(n=83)$ most of them had inappropriate school bag weight (85.5\%), whereas (14.5\%) school bag weight was appropriate and (67\%) students had tilted in the shoulders. Our finding suggested that heavy school bags contributed to the presence of pain and shoulder tilt, whereas long duration of carrying school bag did not affect shoulder tilt. Thus, in future, education for parents must be conducted to make sure to prevent students from carrying bags exceeding the acceptable standard limit.
\end{abstract}

KEY WORDS: SCHOOL BAG, ELEMENTARY SCHOOL, POSTURE, PAIN

\section{INTRODUCTION}

It is well known that schoolbag has effects on the posture of early school students. Studies have revealed that the prevalence of musculoskeletal issues in school children due to heavy school bags is increasing; therefore, it

\section{ARTICLE INFORMATION:}

*Corresponding Author: shahryf@hotmail.com Received $17^{\text {th }}$ Aug, 2018

Accepted after revision $29^{\text {th }}$ Sep, 2018

BBRC Print ISSN: 0974-6455

Online ISSN: 2321-4007 CODEN: USA BBRCBA

\%”. Thomson Reuters ISI ESC / Clarivate Analytics USA and

: Crossref Indexed Journal

NAAS Journal Score 2018: 4.31 SJIF 2017: 4.196

- A Society of Science and Nature Publication, Bhopal India 2018. All rights reserved.

Online Contents Available at: http//www.bbrc.in/

DOI: $10.21786 / \mathrm{bbrc} / 11.3 / 8$ has become a concern, (Chow et al. 2010, Shamsoddini, et al. 2010). Earlier studies have shown that carrying heavy school bags has harmful effects on the children's musculoskeletal systems such as increasing in postural sway, and trunk muscle activity levels, Dianat et al. 2013). Students cannot carry heavy loads due to their 
size and weight. Thus, carrying heavy school bags leads to schoolbag-related injuries for children, Watson et al., (2003). According to doctors and physical therapists, the schoolbag weight should not exceed $10-15 \%$ of the students' body weight to avoid musculoskeletal problems, Several workers ( Murphy et al.2007, Dockrell et al. 2013, Al-Saleem et al. 2016 and Dowshen, 2017) have found the prevalence of back pain among school students by evaluating the school bags weight about their weight. Out of 2567 school students, 1860 (72.46\%) were carrying schoolbags more than the acceptable standard. The results have shown that female student's school bags are more substantial than male student school bags, and $42 \%$ of the school students reported back pain.

Body mechanics education depends on the researcher that assesses the effects of mechanical loading or stress on controlling and supporting the spine. The mechanism of loading could be compression, torque, bending, shear, and tension or a summation of these forces to perform functional tasks from the dynamic nature, Lieber et al. (2000). Excessive forces working on the spine can cause a dynamic deformation of the spine structure the human body can reduce pain stimulation by lowering mechanical stress thus contribute to pain management Lieber et al.2000 The majority of the studies focused on the schoolbag weight as the most important factor affecting the musculoskeletal system, while there are also other factors such as duration and method of carrying schoolbags affecting the musculoskeletal system, (Dianat et al. 2013, Dockrell et al. (2015) and Patil et al. 2016).

Carrying the school bag over one shoulder makes the student lean to one side due to the extra weight which harms the student by causing back pain, shoulder and neck strain. If the school bag is placed in a wrong way over the shoulders, it could lead to back, shoulder and neck pain because the student tries to resist the weight's force that pulls backward by bending forward which causes compression to the spine. Also, carrying school bag incorrectly causes bad posture Pascoe et al. (1997). Dianat et al. (2014) reported that musculoskeletal symptoms prevalent for 307 primary school students were caused by school bags. Results have shown that the shoulders were most affected body region among the sample with (70\%), then wrists/hands (18.5\%), upper back (13.6\%) and low back (8.7\%), while no symptoms were noted for the lower limbs, (Dianat et al. 2013) .

The basic assumption based on the biomedical model is that the maturing spine cannot handle the mechanical load of the backpack sufficiently Reneman et al. (2006). A previous study has shown that head, cervical spine and shoulder alterations in posture throughout gait terminations in student due to load carriage. Carrying more than the standard limit for schoolbag weight has effects on the posture of the head, cervical spine, and shoulder throughout gait terminations. The posture of the head became more forward, while it affected the shoulder to be more rounded and tilted Reneman et al. 2014, Mwaka et al. (2014). Center of gravity has a significant effect on schoolbag weight and in consideration of proper carrying techniques. Different carrying bag techniques is one of the significant factor on posture and gait of students aged between $11 \pm 13$ years old, there is no difference in the lateral spinal deviation between two-strap backpack and students without the bag, Nevertheless, two-strap school bag reduced carrying stress on the student back, neck and shoulders, (Pascoe et al.1997, Skoffer et al. 2007, Mwaka et al. 2014). Moreover confirmed the musculoskeletal pain as result of the heavy backpack.

The literature has demonstrated the detrimental effects of carrying heavy school bags on school students. Studies have revealed that the prevalence of musculoskeletal issues in school students due to heavy school bags is increasing. There was a lack of data about the effect of school bags on body mechanics of children at Saudi Arabia. So, we this study aimed to assess the effect of heavy school bag on the student at elementary school body mechanics in Riyadh. In this study, we took in consideration factors that contribute in heavy bags and the duration of carrying the bag.

\section{MATERIALS AND METHODS}

This study was carried out in primary schools in Riyadh, Saudi Arabia between Augusts to November 2017. It was an observational cross-sectional study. The sample size $(n=200)$ divided equally for each gender as 100 males and 100 females. The sample included primary school students between 9-11 years old (third grade to fifth grade). We excluded students with congenital deformity, history of accident, students younger than 9 years, and older than 11 years, obese students. Multistage cluster sampling was used, thus we divided Riyadh into regions or clusters.

The schools were selected from eastern region, and students were chosen randomly. The participants in each school were waiting in a classroom and numbers were distributed to them randomly so we called them by the number then they came to do the assessment. One assessor measured the student weight and their bag weight, and examined student bags whether it was one/two strap, loose/tight, width of strap, and its contents. Second assessors were interviewed by self-designed questionnaire, and the other assessors were measured with Palpation Meter (PALM).

The questionnaire was developed to cover the areas we wanted to collect in this study. There were 22 questions about demographic details, pain, duration of carrying the school of bag, and whether they are educated about 
the topic. The measurement tool that has been used in this study is valid and reliable tool called palpation meter (PALM) Petrone et al. (2003), Kellis et al. (2010). This tool allows to determine skeletal asymmetry and then locate the point of asymmetry by making measurements at various landmarks in the body. Also, we used scale to weigh the students and their bags. Before visiting schools, we contacted the school principal to permit the conduct of the study. Informed consent form was sent to the parents of the student for signed consent. All details of the study delivered to the parents before the start of the study.

\section{DATA ANALYSIS}

The calculated data entered into Microsoft Excel. Categorical variables represented in frequencies and percentage. Mean and Standard Deviation used for continuous variables. The data analysis used Chi-square test to compare proportion the difference for various variables. A statistical package was SPSS version 22 used for statistical analysis of the data. The P-value $<0.05$ was considered the level of significance. Appropriate diagrams have also been used.

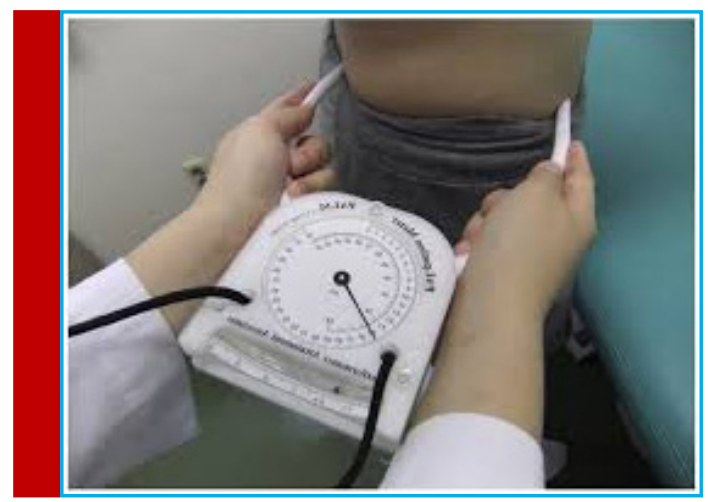

\section{RESULTS AND DISCUSSION}

A total of 200 students from 4 different schools participated in the study. The average age was 9.58 years and the SD was 0.711. There were (100) 50\% male and (100) 50\% female. There were 110 (55\%) third grade (9 years), 64 (32\%) fourth grade (10 years), and 26 (16\%) fifth grade (11 years). The study found that $83 \%$ of the students had inappropriate schoolbag weight and 17\% appropriate as seen in (Fig 1).

It was found that female had more inappropriate school bag weight (54.2\%), while this was $45 \%$ for students. The percentage of students with inappropriate school bag weight of each age group was highest for students with 10 years (90.6\%), then 9 years (80\%) and lowest in 11 years $(76.9 \%)$ see Table 1 . Students who were educated about the effects of school bag on body mechanics were less $(32.5 \%)$ than who were not educated (57.5\%). All the students had backpack and carried their backpacks over two shoulders and most of the bags had wide strap (91.5\%) and loose strap (67.5\%), whereas (8.5\%) of their bags had thin strap and (32.5\%) tight strap. The mean weight of school bags was 4.82 $\pm 1.536 \mathrm{~kg}$ (Table 2). It was found that students who carried books according to their daily schedule were (84\%) while (16\%) did not. The majority of male students (66\%) and female students (78\%) had extra bag content. Less than half of the students reported pain $(41.5 \%)$, and the rest $(58.5 \%)$ of them did not. The students who reported pain $(n=83)$ most of them had inappropriate school bag weight (85.5\%), whereas (14.5\%) school bag weight had appropriate school bag (Table 1).

The most area of pain reported was shoulder (70\%), then $(18 \%)$ in back. and the least reported was in their neck (12\%). Among the students who reported pain, the majority felt pain while carrying the bag (79.5\%), after carrying the bag (14.5\%), and $6 \%$ had felt it all the time

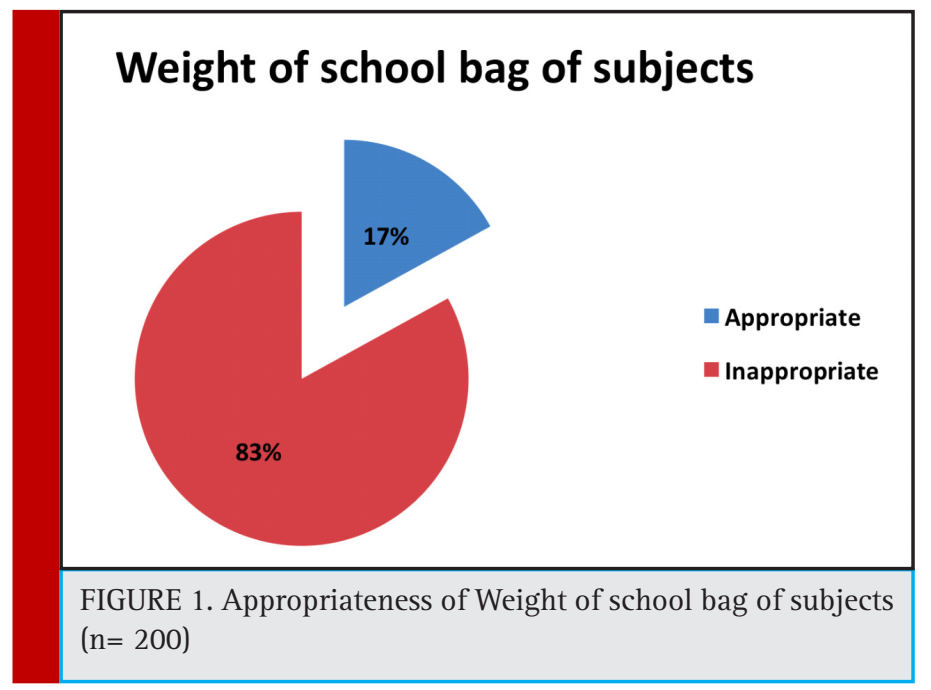


Fayz S Al Shahry et al.

\begin{tabular}{|c|c|c|c|c|c|}
\hline & & \multirow[b]{2}{*}{ Appropriate } & \multirow[b]{2}{*}{ Not appropriate } & \multirow[t]{2}{*}{ Chi square } & \multirow[t]{2}{*}{ P-value } \\
\hline & & & & & \\
\hline \multirow[t]{3}{*}{ When do you feel the pain? $(n=83)$} & While carrying the bag & $7(58.3 \%)$ & $59(83.1 \%)$ & \multirow[t]{3}{*}{9.224} & \multirow[t]{3}{*}{0.010} \\
\hline & After carrying the bag & $2(16.7 \%)$ & $10(14.1 \%)$ & & \\
\hline & All the time & $3(25.0 \%)$ & $2(2.8 \%)$ & & \\
\hline \multirow{3}{*}{$\begin{array}{l}\text { What is the level of your pain? } \\
(n=83)\end{array}$} & Mild & $2(16.7 \%)$ & $36(50.7 \%)$ & \multirow[t]{3}{*}{12.813} & \multirow[t]{3}{*}{0.002} \\
\hline & Moderate & $5(41.7 \%)$ & $30(42.3 \%)$ & & \\
\hline & Severe & $5(41.7 \%)$ & $5(7 \%)$ & & \\
\hline \multirow{2}{*}{$\begin{array}{l}\text { Gender } \\
(\mathrm{n}=200)\end{array}$} & Female & $5(20 \%)$ & $46(42.2 \%)$ & \multirow[t]{2}{*}{4.252} & \multirow[t]{2}{*}{0.039} \\
\hline & Male & $20(80 \%)$ & $63(57.8 \%)$ & & \\
\hline \multirow{2}{*}{$\begin{array}{l}\text { Educated about this topic before } \\
(\mathrm{n}=200)\end{array}$} & Yes & $13(38.2 \%)$ & $52(31.3 \%)$ & \multirow[t]{2}{*}{0.614} & \multirow[t]{2}{*}{0.433} \\
\hline & No & $21(61.8 \%)$ & $114(68.7 \%)$ & & \\
\hline \multirow{2}{*}{$\begin{array}{l}\text { Tilt } \\
(\mathrm{n}=200)\end{array}$} & Yes & $25(18.7 \%)$ & 109(81.3\%) & \multirow[t]{2}{*}{0.790} & \multirow[t]{2}{*}{$0 . .374$} \\
\hline & No & $9(13.6 \%)$ & $57(86.4 \%)$ & & \\
\hline \multirow{2}{*}{$\begin{array}{l}\text { Tilt side } \\
(\mathrm{n}=134)\end{array}$} & Right & $17(68.0 \%)$ & $69(63.3 \%)$ & \multirow[t]{2}{*}{0.195} & \multirow[t]{2}{*}{0.659} \\
\hline & Left & $8(32.0 \%)$ & $40(36.7 \%)$ & & \\
\hline \multirow{3}{*}{$\begin{array}{l}\text { Where do you feel pain exactly? } \\
(\mathrm{n}=83)\end{array}$} & Neck & $1(8.3 \%)$ & $9(12.7 \%)$ & \multirow[t]{3}{*}{2.236} & \multirow[t]{3}{*}{0.327} \\
\hline & Shoulder & $7(58.3 \%)$ & $51(71.8 \%)$ & & \\
\hline & Back & $4(33.3 \%)$ & $11(15.5 \%)$ & & \\
\hline \multirow{2}{*}{$\begin{array}{l}\text { Do you feel any pain? } \\
(\mathrm{n}=200)\end{array}$} & Yes & $12(14.5 \%)$ & $71(85.5 \%)$ & \multirow[t]{2}{*}{0.650} & \multirow[t]{2}{*}{0.420} \\
\hline & No & $22(18.8 \%)$ & 95(81.2\%) & & \\
\hline \multirow{3}{*}{$\begin{array}{l}\text { Age in years } \\
(\mathrm{n}=200)\end{array}$} & 9 & $22(64.7 \%)$ & $88(53.0 \%)$ & \multirow[t]{3}{*}{4.019} & \multirow[t]{3}{*}{0.134} \\
\hline & 10 & $6(17.6 \%)$ & $58(34.9 \%)$ & & \\
\hline & 11 & $6(17.6 \%)$ & $20(12.0 \%)$ & & \\
\hline
\end{tabular}

\begin{tabular}{l} 
Table 2. The mean of school bag weight \\
\hline
\end{tabular}

(6\%). Also, among those students who reported pain most of them had mild level of pain (46\%), then moderate pain (42\%) and very few had severe pain (12\%). According to the age group, pain was highest among student who age 11 years $(n=26) 13(50 \%)$ and lowest in 9 years $(n=110) 41(37.2 \%)$. There was no significant difference between the prevalence of pain between male $(49.4 \%)$ and female (50.6\%). We found that carrying the bag in morning line increase the incidence of pain as (50\%) who have answered yes to carrying it in the morning have pain whereas $(3.87 \%$ ) who have not carry the bag in the morning line have pain see Table 3.

Students who had pain and tilt were 52 (26\%), 19 $(45.2 \%)$ of them were female, and $33(80.5 \%)$ were male see Table $4.134(67 \%)$ students had tilt in the shoulders and 67 (33\%) of them did not have any tilt. From the students who had tilt in their shoulders 19\% had schoolbag weight appropriate while $81 \%$ had inappro-

\begin{tabular}{|l|l|l|l|l|}
\hline \multicolumn{2}{|l|}{ Table 3. Carrying school bag during morning line * pain } \\
\hline \multicolumn{2}{|l|}{} & \multicolumn{2}{l|}{ Do you feel any pain? } & \\
\hline & & Yes & No & Total \\
\hline \multirow{2}{*}{$\begin{array}{l}\text { Do you carry your bag while } \\
\text { standing in the school morning } \\
\text { line? }\end{array}$} & Yes & $22(26.6 \%)$ & $22(18.8 \%)$ & $44(22 \%)$ \\
\cline { 2 - 6 } & No & $61(73.4 \%)$ & $95(81.2 \%)$ & $156(78 \%)$ \\
\hline Total & & $83(100.0 \%)$ & $117(100.0 \%)$ & $200(100.0 \%)$ \\
\hline
\end{tabular}




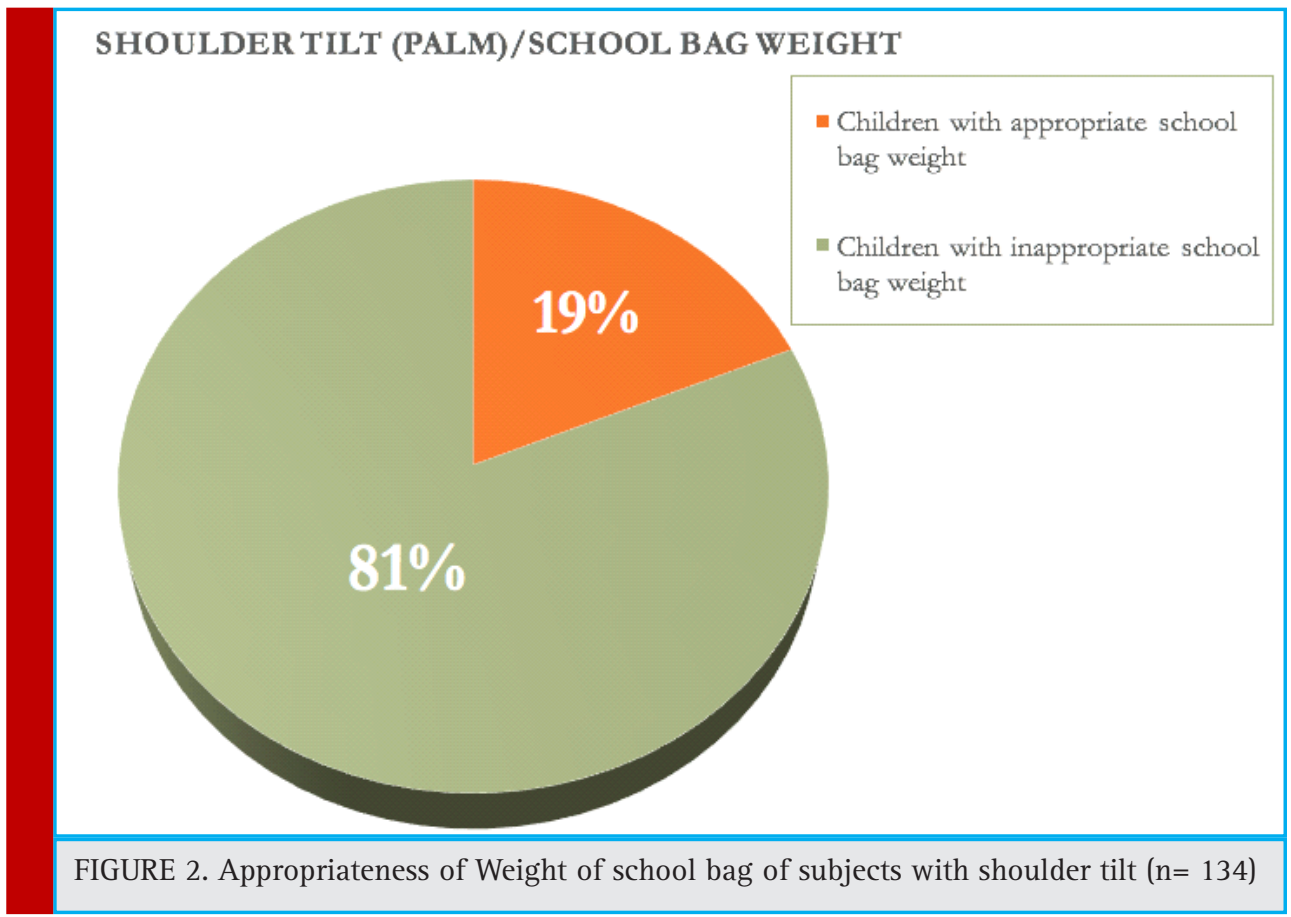

priate bag weight (Figure 2). There was variety in the degrees of shoulders tilt from 1 to 4 degrees. Out of the students with shoulder tilt $(n=134)$ the majority were male $(61.9 \%)$, whereas $(38.1 \%)$ of them were female. We investigated the link between the school bag weight and the presence of tilt in shoulders in each gender. It was found that out of the male with shoulder tilt $(n=83)$ most of them carried school bag with inappropriate weight $(75.9 \%)$, also in female $(n=51)$ the majority of them carried school bag with inappropriate school bag weight (90.1\%) see Table 1.
In this study, we investigated the school bag weight concerning the student body weight. $83 \%$ of the students had school bag weight exceeding the standard limit range (10\%) the highest limit according to the Ireland Republic, European and Health Promotion Board of Singapore guidelines and only 17\% had an appropriate bag weight, Al-Saleem et al. (2016). Alsaleem study found that $72.46 \%$ of their sample size had inappropriate school bag weight. Approximately the percentage was similar between our study and theirs, Al-Saleem et al. (2016). We found that female bags weight

\begin{tabular}{|c|c|c|c|c|c|}
\hline \multicolumn{6}{|l|}{ Table 4. Gender comparison } \\
\hline \multirow{2}{*}{ Female $100(50 \%)$} & & \multicolumn{2}{|c|}{ Gender $(n=200)$} & \multirow[t]{2}{*}{ Chi square } & \multirow[t]{2}{*}{$\mathrm{P}$-value } \\
\hline & & $\begin{array}{l}\text { Male } 100 \\
(50 \%)\end{array}$ & & & \\
\hline \multirow{2}{*}{$\begin{array}{l}\text { Is the schoolbag weight appropriate } \\
(10 \% \text { of the student's body weight }) \\
(\mathrm{n}=200)\end{array}$} & Appropriate & $5(20 \%)$ & $20(80 \%)$ & \multirow{2}{*}{0.650} & \multirow{2}{*}{0.420} \\
\hline & Not appropriate & $46(42.2 \%)$ & $63(57.8 \%)$ & & \\
\hline \multirow{2}{*}{ Pain and tilt $(\mathrm{n}=83)$} & Yes & $19(45.2 \%)$ & $33(80.5 \%)$ & \multirow[t]{2}{*}{11.017} & \multirow{2}{*}{0.001} \\
\hline & No & $23(54.8 \%)$ & $8(19.5 \%)$ & & \\
\hline \multirow{2}{*}{ Tilt (n=200) } & Yes & $49(74.2 \%)$ & $17(25.8 \%)$ & \multirow[t]{2}{*}{23.157} & \multirow{2}{*}{0.001} \\
\hline & No & $51(38.1 \%)$ & $83(61.9 \%)$ & & \\
\hline \multirow{2}{*}{ Bag Content $(n=200)$} & Necessary things & $22(22.0 \%)$ & $34(34 \%)$ & \multirow{2}{*}{3.571} & \multirow{2}{*}{0.059} \\
\hline & Extra things & $78(78 \%)$ & $66(66 \%)$ & & \\
\hline
\end{tabular}




\begin{tabular}{|l|l|l|l|l|}
\hline \multicolumn{6}{|l|}{ Table 5. Carrying school bag during morning line * tilt } \\
\hline & & \multicolumn{2}{|c|}{ Tilt } & \\
\hline & & No & Yes & Total \\
\hline $\begin{array}{l}\text { Do you carry your bag while standing } \\
\text { in the school morning line? }\end{array}$ & Yes & $19(43.2 \%)$ & $25(56.8 \%)$ & $44(100.0 \%)$ \\
\cline { 2 - 6 } & No & $47(30.1 \%)$ & $109(69.8 \%)$ & $156(100.0 \%)$ \\
\hline Total & & $66(33 \%)$ & $134(67 \%)$ & $200(100.0 \%)$ \\
\hline
\end{tabular}

is slightly higher than male. Likewise, Alsaleem et al. results have shown that female student's school bags are heavier than male student's school bags. Also, a study found that female carried heavier schoolbags than male, Kellis et al. (2010).

The mean weight of school bags was $4.82 \pm 1.536 \mathrm{Kg}$, ranging from $2 \mathrm{~kg}$ to $14 \mathrm{~kg}$, statistically significant at 0.05. All the students had a backpack and carried their back packs over two shoulders. Likewise, in Dockrell, Simms, and Blake study the mean schoolbag weight (4.8 $\pm 1.43 \mathrm{~kg}$ ) and the majority (85\%) carried their school bag over two shoulders. According to the age group, the percentage of students with inappropriate school bag weight was highest for students with ten years (90.6\%). Inconsistent with another study, the relative bag weight was significantly heavier in the younger age group (ages 6-8 years), Kellis et al. (2010). Pain was highest among student with 11 years' students $(n=26) 13(50 \%)$ and lowest in 9 years $(n=110) 41(37.2 \%)$.

According to the measurement findings (PALM) we found that out of the students with shoulder tilt $(n=134)$ $51(38 \%)$ of them were female while $83(61.9 \%)$ of the male. We concluded that males have more shoulder tilt than female. Thus, the shoulder tilt correlated with the schoolbag weight $(n=134)$, as a male with shoulder tilt and carried inappropriate school bag weight 63(57.8\%) were more than female with shoulder tilt and carried inappropriate school bag 46(42.2\%). The percentage of students who had shoulders tilt with inappropriate bag weight (81\%) was higher than those with appropriate school bag weight (19\%).this goes in line with the observations and recommendations of Dockrell et al.(2015) and Patilet al.(2016) .

The majority of male (66\%) and female (78\%) had extra bag items such as coloring books, and toys. In the Dockrell et al. study, it was also found that the students' bags had additional details such as sports items and musical instrument. These extra stuff increased the load carriage on students. Inappropriate school bag increased the incidence of pain and tilt in the shoulders. Carrying school bag during morning line increased the incidence of pain as most of the students who took their bags during morning line reported pain (50\%). However, it did not show any evidence of increasing the shoulder tilt see Table 5 .

The most area of pain reported was a shoulder (70\%) this is matched the findings in Reneman et al.(2006), then (18\%) in back. And the least reported was in their neck (12\%). Similarly, in the study of Dockrell et al. (2015), the shoulders and the back were the most frequently reported areas of schoolbag-related discomfort. Students who reported pain $(n=83)$ the majority felt pain while carrying the bag (79.5\%), then after carrying the bag (14.5\%), and the least had felt it all the time (6\%). Students who reported pain $(n=83)$ Most of them had a mild level of pain (46\%), then moderate pain (42\%) and very few had severe pain (12\%) this matched the result of Spiteri et al. 2017. education for (32.5\%) were made about the effect of heavy school bags on their body mechanics, but it was reflected negatively as we saw that $(80 \%)$ of them had inappropriate school bag weight this indicated the poor response of the student to the education, may due to habitual attitude witch need long observation and correction by the family and the school teachers.

The students who had both pain and tilt were 52 students whom 19 (45.2\%) female and 33 (80.5\%) male students with a P-value 0.001. Thus, not every student with tilt was reported pain and vice versa. The presence of shoulders tilt was higher than the incidence of pain this goes in line with the findings of Ghousia et al. (2018).

Limitations of this study was it is only conducted in one region and Strengths of this study were that it considered other factors besides the bag's weight; the books should be unified from Ministry of Education for both public and private schools.

\section{CONCLUSION}

This study provided evidence that school bag weight has an effects on body biomechanics which causes shoulders tilt, and it also increased the incidence of pain. So, in future, education for parents must be conducted to make sure to prevent students from carrying bags exceeding the acceptable standard limit. The percentage of students with inappropriate school bag weight is high, so further research should investigate in depth the reasons for carrying heavy bags among primary school students.

\section{REFERENCES}

Chow DH, Ou ZY, Wang XG, Lai A. (2010) Short-term effects of backpack load placement on spine deformation and repositioning error in schoolchildren. Ergonomics.;1; 53(1):56-64. 
Dianat I, Javadivala Z, Allahverdipour H. (2011) School bag weight and the occurrence of shoulder, hand/wrist and low back symptoms among Iranian elementary schoolchildren. Health Promot Perspect. 25; 1(1):76-85.

Hough PA, Nel M, Smit JE, Malan E, van der Watt M, Deacon AF, Grobler L, Bester AM. (2006) The Influence of carrying a school bag on the developing spine. Children's Health Care. 1;35(4):339-48.

Shamsoddini AR, Hollisaz MT, Hafezi R. (2010) Backpack weight and musculoskeletal symptoms in secondary school students, Tehran, Iran. Iranian journal of public health. 39(4):120.

Dianat I, Javadivala Z, Asghari-Jafarabadi M, Asl Hashemi A, Haslegrave CM. (2013) The use of schoolbags and musculoskeletal symptoms among primary school children: are the recommended weight limits adequate? Ergonomics. 1; 56(1):79-89.

Watson KD, Papageorgiou AC, Jones GT, Taylor S, Symmons DP, Silman AJ, Macfarlane GJ. (2003) Low back pain in schoolchildren: the role of mechanical and psychosocial factors. Archives of disease in childhood. 1; 88(1):12-7.

Steven Dowshen, MD Backpack Safety [Internet]. Kidshealth. org. 2017 [cited 25 April]. Available from: http://kidshealth. org/en/parents/backpack.html\#.

Dockrell S, Simms C, Blake C. (2013) Schoolbag weight limit: can it be defined?. Journal of School Health. 2013; 1;83(5):36877.

Al-Saleem SA, Ali A, Ali SI, Alshamrani AA, Almulhem AM, Al-Hashem MH. (2016) A Study of School Bag Weight and Back Pain among Primary School Children in Al-Ahsa, Saudi Arabia. Epidemiology (Sunnyvale, Calif.); 6(1).

Murphy S, Buckle P, Stubbs D. (2007) A cross-sectional study of self-reported back and neck pain among English schoolchildren and associated physical and psychological risk factors. Applied ergonomics. 30; 38(6):797-804.

Lieber SJ, Rudy TE, Boston JR. (2000) Effects of body mechanics training on performance of repetitive lifting. American Journal of Occupational Therapy. 1; 54(2):166-75.

Patil MA, Sumana S, Shagale N. (2016) Awareness of parents about characteristics and carrying habits of backpack and its comparison with behavioral practices of their children. Pediatric Review: International Journal of Pediatric Research. 3(03)

Dianat I, Karimi MA. (2014) Association of parental awareness of using schoolbags with musculoskeletal symptoms and carrying habits of schoolchildren. The Journal of School Nursing. 30(6):440-7.

Dockrell S, Simms C, Blake C. (2015) Schoolbag carriage and schoolbag-related musculoskeletal discomfort among primary school children. Applied ergonomics.51:281-90.

Pascoe DD, Pascoe DE, Wang YT, Shim DM, Kim CK. (1997) Influence of carrying book bags on gait cycle and posture of youths. Ergonomics. 40(6):631-40.
Reneman MF, Poels BJ, Geertzen JH, Dijkstra PU. (2006) Back pain and backpacks in children: Biomedical or biopsychosocial model? Disability and rehabilitation. 1; 28(20):1293-7.

Mo SW, Xu DQ, Li JX, Liu M. (2013) Effect of backpack load on the head, cervical spine and shoulder postures in children during gait termination. Ergonomics. 1;56(12):1908-16.

Balamurugan J. (2014)School bags and musculoskeletal pain among elementary school children in Chennai city. International journal of medical science and clinical Invention. 1(6):302-9.

Mwaka ES, Munabi IG, Buwembo W, Kukkiriza J, Ochieng J. (2014) Musculoskeletal pain and school bag use: a crosssectional study among Ugandan pupils. BMC research notes. 9;7(1):222.

Skoffer B. (2007) Low back pain in 15-to 16-year-old children in relation to school furniture and carrying of the school bag. Spine. 15; 32(24):E713-7.

da Costa BR, Armijo-Olivo S, Gadotti I, Warren S, Reid DC, Magee DJ. (2010) Reliability of scapular positioning measurement procedure using the palpation meter (PALM). Physiotherapy. Mar 31; 96(1):59-67.

Petrone MR, Guinn J, Reddin A, Sutlive TG, Flynn TW, Garber MP. (2003)The accuracy of the palpation meter (PALM) for measuring pelvic crest height difference and leg length discrepancy. Journal of orthopaedic \&t sports physical Therapy. Jun; 33(6):319-25.

Kellis E, Emmanouilidou M. (2010) The effects of age and gender on the weight and use of schoolbags. Pediatric Physical Therapy. Apr 1; 22(1):17-25.

Spiteri K, Busuttil ML, Aquilina S, Gauci D, Camilleri E, (2017) Schoolbags and back pain in children between 8 and 13 years: a national study. Br J Pain 11: 81-86.

Ghousia Shahid, Khalid Aziz, Abida Arif and Muhammad Faisal Fahim*(2018)Prevalence of Musculoskeletal Pain due to Heavy Backpacks in School going Children of Karachi. International Journal of Physical Medicine \& Rehabilitation, 6(3) 471

Prevalence of Musculoskeletal Pain due to Heavy Backpacks in School going Children of Karachi Ghousia Shahid, Khalid Aziz, Abida Arif and Muhammad Faisal Fahim The 7 Best Posture-Saving Backpacks, According to a Chiropractor http:// nymag.com/strategist/article/best-backpacks-students-andback-pain-2017.html

Priyanka Kumbhare (2018) Prevalence of Musculoskeletal Pain due to Heavy Backpacks in School going Children of Karachi International Journal of Physical Medicine \& Rehabilitation, Fahim et al., Int J Phys Med Rehabil 2018, 6:3

Spiteri K, Busuttil ML, Aquilina S, Gauci D, Camilleri E, et al. (2017) Schoolbags and back pain in children between 8 and 13 years: a national study. Br J Pain 11: 81-86. 